\title{
PEMODELAN ARSITEKTUR ENTERPRISE MENGGUNAKAN METODE TOGAF ADM (STUDI KASUS: SMAN 1 WATUBANGGA)
}

\author{
Noorhasanah.Z $Z^{\# 1}$

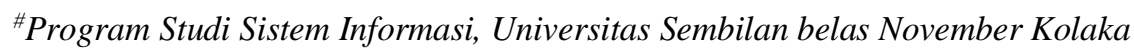 \\ Jalan Pemuda No 339 Kolaka, Sulawesi Tenggara \\ ${ }^{1}$ Noorhasanahzain@gmail.com
}

\begin{abstract}
SMA Negeri 1 Watubangga is one of the schools in Kolaka Regency that implement the flagship program, but the current condition of SMA Negeri 1 Watubangga does not have an integrated information system architecture according to the needs and objectives of the school, this problem arises because the school has not focused on the process development of information systems. Therefore it is necessary design of information system architecture SMA Negeri 1 Watubangga. Architectural modeling in this research using TOGAF Framework (The Open Group Architecture Framework) with ADM (Architecture Development Methode) method. Stages used are the preparation of architectural vision, business architecture, information system architecture, technology architecture, opportunities and solutions and migration plans. The result of this enterprise architecture modeling is the blue print model and framework in integrated school information system modeling to support the needs of SMAN 1 Watubangga.
\end{abstract}

Keywords - Arsitecture modeling enterprise, information system, TOGAF ADM.

\section{Pendahuluan}

Pemanfaatan sistem informasi dalam organisasi adalah kebutuhan dasar dalam menjalankan fungsi bisnis. Penerapan sistem informasi yang salaing tumpang tidih diakibatkan dari sistem yang dikembangkan masing-masing, sehingga tidak terpadu dan terintegrasi dengan baik.

Salah satu penyebab utama dari ini semua adalah karena kurangnya perencanaan dan tanpa memikirkan kunci utama dalam proses pengembangan sistem informasi yaitu pemodelan, pemodelan sistem informasi yang baik harus melihat dari berbagai sudut pandang pengembangan sistem, dimulai dari mendefinisikan arsitektur bisnis yang ada dalam organisasi, mendefinisikan arsitektur data yang akan digunakan, mendefinisikan arsitektur aplikasi yang akan dibangun serta mendefinisikan arsitektur teknologi yang mendukung jalannya sistem informasi tersebut.

Sebelumnya sudah pernah dilakukan penelitian mengenai pemodelan menggunakan TOGAF ADM, seperti penelitian yang dilakukan oleh Yeni Kustiyahningsih, perencanaan arsitektur enterprise menggunakan TOGAF ADM [1]. Penelitian terkait juga pernah dilakukan oleh Novia Widyaningsih, perencanaan arsitektur enterprise menggunakan TOGAF versi 9 studi kasus:dewan kehormatan penyelenggara pemilu (DKPP) [2]. Peneletian lain yang terkait Rahman Rosyidi, Perancangan Pengembangan arsitektur sistem informasi akademik dengan menggunakan togaf (studi kasus:STMIK Amikom Purwokerto) [3].

Penelitian yang dilakukan saaat ini Pemodelan arsitektur enterprice menggunkan TOGAF ADM studi kasus SMA Negeri1 Watubangga yang diharapkan mampu menghasilkan blue print dan sistem informasi yang terintegrasi guna mendukung kebutuhan SMA Negeril Watubangga.

\section{TinJAUAn PUSTAKa}

\section{1 arsitecture enterprise}

Arsitecture enterprise adalah membangun atau merancang teknologi informasi yang akan mengarahkan organisasi sehingga memiliki sistem informasi terpadu dan terintegrasi yang mendukung tujuan organisasi [4]. Sedangkan menurut ahli lain, Arsitecture enterprise merupakan pendekatan logis yang komrehensif untuk merancang dan 
mengimplementasikan sistem secara bersama-sama yang meliputi suatu infrastuktur manajemen, pengklasifikasian, pendefinisian dan rancang koneksitas yang diwujudkan dalam bentuk model dan gambar serta memiliki komponen utama berupa arsitektur bisnis, arsitektur informasi, arsitektur aplikasi dan arsitektur teknologi [5].

\subsection{TOGAF ADM}

TOGAF dikembangkan oleh The Open Group's Architecture Framework pada tahun 1995. Awalnya TOGAF digunakan oleh Departemen Pertahanan Amerika Serikat namun pada perkembangannya, TOGAF banyak digunakan pada berbagai bidang seperti perbankan, industri manufaktur dan juga pendidikan. TOGAF ini digunakan untuk mengembangkan Enterprise Architecture, dimana terdapat metode dan tools yang detil untuk mengimplementasikannya, hal inilah yang membedakan dengan Framework EA (Enterprise Archietecture) lain misalnya Framework Zachman. Salah satu kelebihan menggunakan Framework TOGAF ini adalah karena sifatnya yang fleksibel dan bersifat open source. Elemen penting dari TOGAF adalah Architecture Development Method $(A D M)[6],[7]$.

ADM merupakan metode generik yang berisikan sekumpulan aktivitas yang digunakan dalam memodelkan pengembangan arsitecture enterprise. Metode ini juga bisa digunakan sebagai panduan atau alat untuk merencanakan,merancang, mengembangkan dan mengimplementasikan arsitektur sistem informasi untuk organisasi [7].

TOGAF ADM menyediakan proses yang teruji dan berulang untuk mengembangkan sistem. ADM termasuk membangun kerangka kerja arsitektur, mengembangkan konten arsitektur, transisi, dan mengatur realisasi arsitektur. Semua kegiatan tersebut dilakukan dalam siklus berulang yang berkelanjutan dan terealisasi agar memungkinkan organisasi untuk mengubah perusahaan mereka dengan cara terkontrol dalam menanggapi tujuan bisnis dan peluang [6].

ADM (Architecture Development Method) merupakan hasil dari kerja sama praktisi arsitektur dalam Open Group Architecture. ADM adalah metode generik yang berisi sekumpulan aktivitas yang mempresentasikan progresi dari setiap tahapan ADM dan model arsitektur selalu diselaraskan dengan sasaran dan kebutuhan bisnis. Inti dari ADM adalah pengelolaan kebutuhan, dimana kebutuhan bisnis, sistem informasi, dan arsitektur teknologi selalu diselaraskan dengan sasaran kebutuhan bisnis. Adapun 8 tahapan dalam metodologi TOGAF ADM[9]:

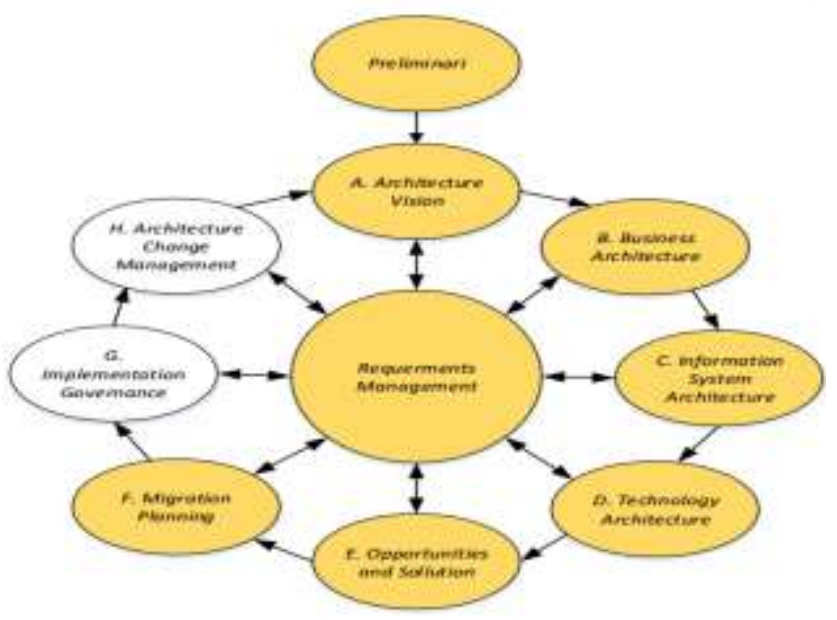

Gambar 1. FASE TOGAF ADM [9]

Berikut ini adalah penjelasan dari masing-masing fase pada TOGAF ADM [6]:

1) Preliminary Phase

Fase Preliminary merupakan tahap awal persiapan perencanaan asitektur enterprise. Tahapan ini dilakukan untuk menentukan framework dan metodologi untuk mengembangkan arsitektur enterprise pada organisasi, mengidentifikasi stakeholder yang terlibat pada pencipta arsitektur enterprise, serta menentukan ruang lingkup arsitektur eneterprise yang akan dikembangkan. Tujuan dari fase ini adalah untuk meyakinkan setiap orang yang terlibat didalamnya bahwa pendekatan ini berkomitmen untuk kesuksesan dari setian arsitektur yang akan dibuat.

\section{2) Requirements Management}

Requirements Management adalah prose pengelolaan kebutuhan arsitektur diseluruh fase TOGAF ADM. Tujuan dari proses ini adalah untuk menentukan kebutuhan arsitektur enterprise, kebutuhan itu disimpan, lalu dimasukkan ke dalam fase yang sesuai.

\section{3) Fase A : Architecture Vision}

Menciptakan keseragaman pandangan mengenai pentingnya arsitektur enterprise untuk mencapai tujuan organisasi yang dirumuskan dalam bentuk strategi serta menentukan lingkup dari arsitektur yang akan dikembangkan. Pada tahapan ini dibahas mengenai visi dari perancangan arsitektur enterprise yang dilakukan guna mendukung aktifitas bisnis sesuai dengan visi dan misi dari organisasi.

4) Fhase B : Business Architecture 
Pada tahapan ini dilakukan analisis terhadap proses bisnis yang sedang berlangsung saat ini. Arsitektur bisnis berisi starategi aktivitas, organisasi, dan informasi aktivitas utama. Arsitektur bisnis sering diperlukan sebaga sarana untuk menunjukkan nilai aktivitas utama. Arsitektur bisnis sering diperlukan sebagai saran untuk menunjukkan nilai aktivitas dan alur aktivitas yang akan diusulkan sesuai dengan kebutuhan stakeholder.

5) Fhase C : Information System Architecture

Pada tahapan ini dilakukan pemodelan arsitektur sistem informasi yang akan dirancang sesuai dengan hasil sebelumnya, meliputi pemodelan arsitektur data dan pemodelan arsitektur aplikasi serta arsitektur proses. Dalam pelaksanaannya, tidak hanya terpaku kepada arsitektur data terlebih dahulu dan diikuti arsitektur aplikasi, akan tetapi bisa saja pelaksanaannya dilakukan arsitektur aplikasi terlebih dahulu.

6) Fhase D : Technology Archietecture

Arsitktur teknologi berusaha memetakan komponen aplikasi yang didefenisikan pada arsitektur aplikasi kedalam satu set komponen teknologi yang mewakuli komponen software, hardware, dan jaringan, dengan cara membeli ke pihak luar atau konfigurasi oleh organisasi ke dalam platform teknologi.

7) Fase E : Opportunities and Solutions

Fase peluang dan solusi adalah tahap pertama yang langsung berkaitan dengan struktur bagaimana arsitektur target akan dihasilkan. Pada fase E akan dikonsentrasikan pada cara penyampaian arsitektur.

\section{8) Fase F :Migration Planning}

Pada tahapan ini dilakukan penyusunan urutan implementasi sistem didasarkan kepada skala prioritas. Aktivitas fase ini termasuk menilai ketergantungan, biaya dan keuntungan dari berbagai proyek migrasi. Tujuan fase ini untuk memorioritaskan semua paket pekerjaan dan proyek dengan memberikan nilai bisnis pada masing-masing pekerjaan dan proyek, serta melakukan analisis biaya atau bisnis.

\section{9) Fhase G : Implementation Governance}

Pada phase tata kelolah implementasi, proyek dilaksanakan sebagai program rencana dan diolah agar dapat mencapai arsitektur yang diinginkan. Aspek utama pada fase $\mathrm{G}$ adalah memastikan kebutuhan dengan arsitektur yang didefenisikan, bukan hanya oleh proyek implementasi, tetapi juga oleh proyek yang sedang berlangsung dalam perusahaan/sekolah.

10) Fhase $\mathrm{H}:$ Architecture Change management.

Memonitor sistem yang sedang berjalan untuk kepentingan perubahan dan menentukan tahapan bagaimana mengatur perubahan tersebut, mulai dari pemeliharaan sederhana samapai perancangan kembali arsitektur. Tujuan dari fase ini adalah untuk memastikan bahwa arsitektur mencapai nilai target bisnisaslinya, serta membangun dan mendukung arsitektur enterprisendiimplementasikan sebagai arsitektur yang dinamis.

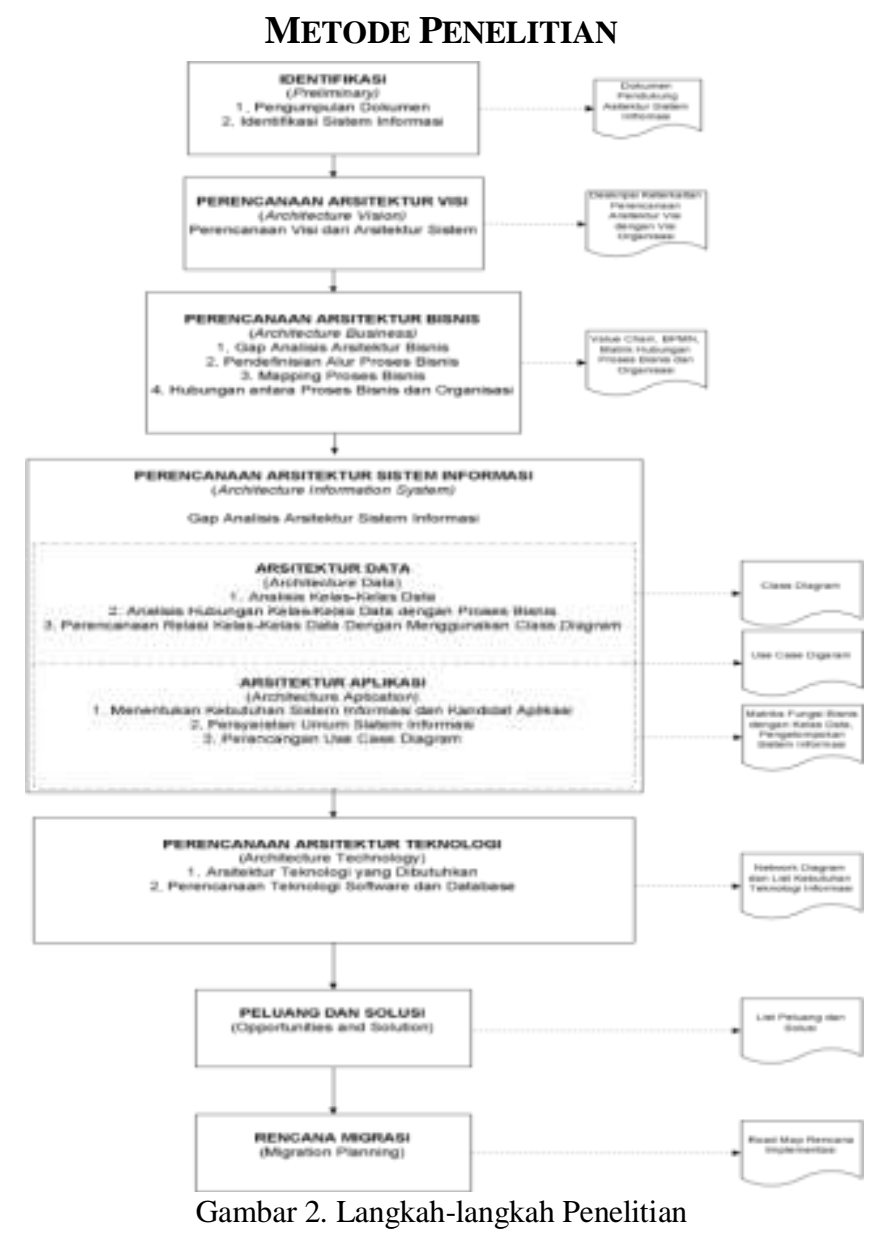

\section{Hasil Dan Pembahasan}

Pemodelan arsitektur enterprise pada penelitian ini mengacu pada pengembangan sistem informasi SMA Negeri1 Watubangga berdasarkan framework TOGAF ADM, dimana dalam kerangka kerja TOGAF terdapat 4 (empat) kategori yaitu arsitektur bisnis, arsitektur data, arsitektur aplikasi, arsitektur teknologi.

Fungsi bisnis yang ada dalam rantai nilai yang sudah ditetapkan, langkah yang dilakukan adalah merumuskan daftar catalog dari proses-proses bisnis yaang ada pada fungsi bisnis utama dan pendukung SMA Negeri1 Watubangga. untuk mendefinisikan fungsi dan layanan yang ada pada masing-masing fungsi bisnis, akan dimodelkan dalam bentuk proses 
bisnis. untuk pemodelan proses bisnis tersebut bissa menggunakan artefak yang sudah disediakan TOGAF $A D M$ atau dengan $U M L$. Dapat dilihat pada gambar :

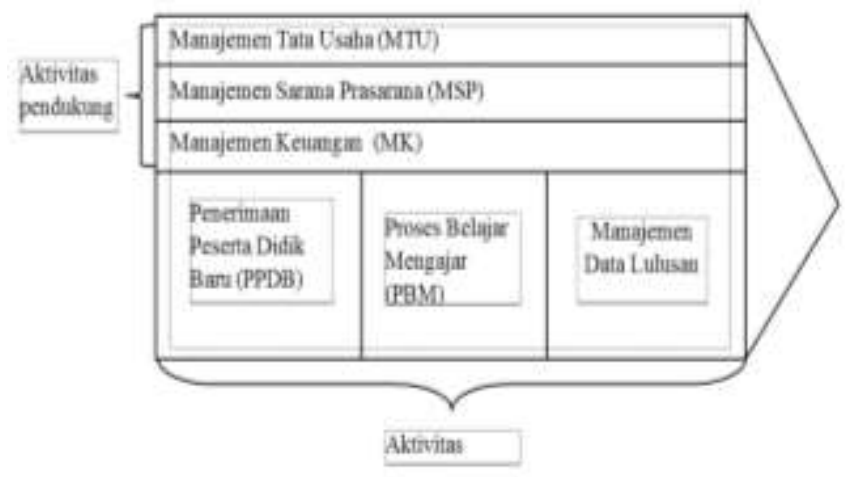

Gambar 3. Value Chain SMA Negeri 1 Watubangga

Berdasarkan Gambar 3, maka deskripsi dari fungsi bisnis tersebut adalah sebagai berikut:

1. Aktivitas Utama

- Penerimaan Peserta Didik Baru (PPDB)

Dapat dideskripsikan sebagai yang meliputi proses Penerimaan Peserta Didik Baru, seleksi siswa baru, sampai dengan pendataan siswa baru

- Proses Belajar Mengajar (PBM)

Merupakan proses program pembelajaran yang berdasarkan pada standar kompetensi lulusan, standar isi, dan peratutan pelaksanaannya, aktivitas akademik yang berhubungan dengan pengelolahan kurikulum, Proses Belajar Mengajar, ujian, pengelolahan nilai ujian, penjadwalan mata pelajaran.

- Manajemen Data Lulusan

Merupakan aktivitas pengelolahan data alumni, pendataan biodata alumni.

2. Aktivitas Pendukung

- Manajemen Tata Usaha (MTU)

Aktivitas sarana prasarana dan prasarana pendukung yang bertujuan memberikan layanan kepada semua komponen sekolah, yang meliputi pengolahan data guru, serta pencatatan administrasi kehadiran serta jadwal mata pelajaran.

- Manajemen Sarana Prasarana (MSP)

Aktivitas pendukung yang berkaitan dengan usaha untukmemberikan dukungan manajemen sarana prasarana khususnya pada aktivitas operasional proses belajar mengajar.

- Manajemen Keuangan (MK)
Merupakan aktivitas yang berkaitan dengan usaha untuk memberikan dukungan manajemen keuangan yang berkisar pada perencanaan anggaran, investasi serta pemeliharaan infrastruktur, sarana dan prasarana organisasi.

\subsection{Perancangan arsitektur sistem informasi 4.1.1. preliminary}

Saat ini SMA Negeri 1 Watubangga mempunyai beberapa software dan aplikasi yang digunakan untuk pengolahan data proses bisnis. Dari hasil observasi ini dihasilkan inventaris sistem aplikasi yangakan dijadikan acuan dasar untuk migrasi jangka panjang. Saat ini aplikasi-aplikasi tersebut belum terintegrasi dan fungsinya hanya untuk kegiatan saja, tidak memiliki server penampung data dan beberapa komponen yang ada dalam sistem aplikasi masih sangat sederhana. SMA Negeri 1 Watubangga telah mengggunakan teknologi software untuk kebutuhan sebagai operating system, keamanan, software pengolahan e-mail, software bahasa pemrograman dan software pengolahan lainnya.

Pemanfaatan aplikasi dan teknologi software dapat dilihat apada tabel berikut ini:

TABEL I

APLiKASI YANG DigUNAKAN SMA NEGERI 1 WATUBANGGA

\begin{tabular}{|c|c|c|}
\hline $\begin{array}{l}\text { Nama } \\
\text { Aplikasi }\end{array}$ & Deskripsi & $\begin{array}{c}\text { Status } \\
\text { Aplikasi }\end{array}$ \\
\hline $\begin{array}{l}\text { Aplikasi } \\
\text { Penerimaan } \\
\text { peserta didik } \\
\text { baru }\end{array}$ & $\begin{array}{l}\text { Yang dimana SMA Negeril Watubangga menggunakan Websait } \\
\text { pada saat pendaftaran secara online agar mempermudah dalam } \\
\text { pendaftaran calon siswa baru` }\end{array}$ & Aktif \\
\hline $\begin{array}{l}\text { Aplikasi } \\
\text { daftar ulang } \\
\text { siswa baru } \\
\text { (registrasi) } \\
\end{array}$ & $\begin{array}{l}\text { Dalam pengolahan dafar ulang siswa baru masih menggunakan } \\
\text { microsoft office word sebagai penginputan data siswa yang harus } \\
\text { daftar ulang }\end{array}$ & Aktif \\
\hline $\begin{array}{l}\text { Aplikasi } \\
\text { penjadwalan }\end{array}$ & $\begin{array}{l}\text { Aplikasi penjadwalan ini masih menggunakan microsoft office } \\
\text { word dalam mengatur penjadwalan baik proses belajar mengajar } \\
\text { maupun mata pelajaran yang akan dipelajari. }\end{array}$ & Aktif \\
\hline $\begin{array}{l}\text { Aplikasi } \\
\text { Nilai siswa }\end{array}$ & $\begin{array}{l}\text { Dalam menginput nilai siswa dapat menggunakan microsoft office } \\
\text { excel agar lebih cepat. }\end{array}$ & Aktif \\
\hline $\begin{array}{l}\text { Aplikasi } \\
\text { kehadiran } \\
\text { guru }\end{array}$ & $\begin{array}{l}\text { Yang dimana kehadiran guru juga sangat penting dalam sekolah } \\
\text { selain untuk mendapatkan tunjangan maupun gaji yang akan } \\
\text { diberikan maka kehadiran guru sangatlah diutamakan terutama } \\
\text { dalam proses belajar mengajar maupun bimbingan konseling } \\
\text { selama masih disekolah, dengan menggunakan microsoft office } \\
\text { excel sebagai alat untuk mempermudah dalam pembuatan } \\
\text { kehadiran, }\end{array}$ & Aktif \\
\hline $\begin{array}{l}\text { Aplikasi } \\
\text { rencana } \\
\text { kerja } \\
\text { anggaran }\end{array}$ & $\begin{array}{l}\text { Untuk lebih mudah dalam perencanaan kerja anggaran maka } \\
\text { microsoft office excel dapat digunakan untuk menjumlah maupun } \\
\text { menginput barang-barang yang akan dibutuhkan }\end{array}$ & Aktif \\
\hline $\begin{array}{l}\text { Aplikasi } \\
\text { administrasi } \\
\text { laboratorium }\end{array}$ & $\begin{array}{l}\text { Dalam administrasi laboratorium dapat menggunakan microsoft } \\
\text { office word apabila barang ataupun alat yang digunakan dapat } \\
\text { terinput apabila ada kekurangan maupun penambahan dapat } \\
\text { diketahui dengan cepat. }\end{array}$ & Aktif \\
\hline $\begin{array}{l}\text { Aplikasi } \\
\text { manajemen } \\
\text { data lulusan }\end{array}$ & $\begin{array}{l}\text { Yang dimana dalam pembuatan data lulusan seperti SKHU } \\
\text { maupun ijazah dapat menggunakan microsoft office word sebagai } \\
\text { penginput agar lebih cepat dalam pembuatannya. }\end{array}$ & Aktif \\
\hline $\begin{array}{l}\text { Aplikasi } \\
\text { manajemen } \\
\text { tata usaha }\end{array}$ & $\begin{array}{l}\text { Dalam aplikasi manajemen tata usaha ini masih menggunakan } \\
\text { microsoft office excel untuk mengelolah data dan rekapitulasi } \\
\text { kepangkatan guru yang dibuat. }\end{array}$ & Aktif \\
\hline
\end{tabular}

TABEL II

Kondisi Sistem DAN TeKNOLOGi SAAT INI 


\begin{tabular}{|l|l|l|}
\hline No & $\begin{array}{l}\text { Pemanfaatan } \\
\text { TIK }\end{array}$ & \multicolumn{1}{|c|}{ Keterangan } \\
\hline 1 & Pengolahan & $\begin{array}{l}\text { Menggunakan aplikasi office, seperti } \\
\text { word, excel dan power point, Data } \\
\text { kebanyakan dalam bentuk tercetak, dan } \\
\text { beberapa softcopy. }\end{array}$ \\
\hline 2 & fistem Operasi & Semuanya menggunakan MS. Windows \\
\hline 3 & rocessor & $\begin{array}{l}\text { Sebagian besar menggunakan Intel Core } \\
\text { i3 }\end{array}$ \\
\hline 4 & Alat Input & Keyboard dan Mouse \\
\hline 5 & Alat cetak & Epson L210, Canon IP2700 \\
\hline
\end{tabular}

Dari Tabel dapat didefenisikan bahwa pengembangan aplikasi yang memfokuskan hanya pada penerimaan peserta didik baru agar dalam pengolahan datanya lebih cepat sehingga menggunakan website, sedangkan pada aplikasiaplikasi lainnya hanya menggunakan sistem operasi Microsoft Office sebagai alat bantu dalam pengolahan data lainnya karena kurangnya tenaga kerja yang bisa mengembangkan aplikasi maka SMA Negeri 1 Watubangga hanya memfokuskan dalam pembuatan website.

\subsubsection{Architecture Vision}

Berdasarkan visi, misi, tujuan dan sasaran SMA Negeri 1 Watubangga, dapat ditarik kesimpulan bahwa visi arsitektur Sistem Informasi SMA Negeri1 Watubangga adalah sebagai berikut:

1. Arsitektur sistem informasi sekolah yang dibuat sebagai pendukung SMA Negeri 1 Watubangga untuk mencapai tujuannya, yaitu:

a. Memberikan layanan yang diperlukan civitas akademika dan stakeholder secara memuaskan, andal dan terjangkau

b. Menaikkan mutu pelayanan sesuai dengan misi pendidikan

c. Memberikan informasi yang akurat ke dalam dan luar institusi

2. Terdiri dari unit-unit sistem informasi yang dikelola masing-masing oleh setiap unit dan terintegrasi dengan sistem di SMA Negeri 1 Watubangga.

3. Dapat diakses oleh semua civitas akademika dan stakeholders SMA Negeril Watubangga dengan tingkat kebutuhan, peran dan pengetahuan yang berbeda. Setelah meninjau tujuan badan pendidikan dan karakter sistem informasinya, disimpulkan bahwa untuk membangun enterprise architecture institusi pendidikan dibutuhkan metode yang bersifat:
a. Bersifat generik.
b. Mampu menyatukan artefak-artefak yang memiliki standar yang berbeda-beda.
c. Mudah diimplementasikan.

d. Tidak rentan terhadap perubahan (amdal).

e. Memiliki tolak ukur dan kontrol dalam menentukan tingkat keberhasilan dalam pelaksanaan IT Governance.

Kegiatan persiapan dan inisiasi yang diperlukan untuk memenuhi direktif bisnis untuk arsitektur enterprise, termasuk definisi kerangka Arsitektur Organisasi dan definisi prinsip-prinsip. Sebagai sekolah yang membutuhkan arsitektur sistem informasi menggunakan Framework TOGAF harus sejalan dengan kerangkanya dan juga memastikan tingkat visibilitas, bimbingan kontrol, dan yang akan mendukung semua persyaratan arsitektur.

Secara khusus, visibilitas peningkatan pengambilan keputusan di tingkat bawah menjamin pengawasan pada tingkat yang sesuai dalam keputusan yang mungkin memiliki konsekuensi yang strategis bagi organisasi.

\subsubsection{Business Architecture}

Pada tahapan ini dilakukan pemodelan arsitektur terhadap tahap-tahap proses bisnis yang terkait langsung dengan area pelayanan penerimaan peserta didik baru (PPDB), proses belajar mengajar (PBM), manajemen data lulusan (MDL), manajemen tata usaha(MTU), manajemen sarana prasarana (MSP), manajemen keuangan (MK), yang merupakan bisnis utama yang ada pada SMA Negeri1 Watubangga. Dalam proses pemodelan arsitektur bisnis ini menggunakan tools use case diagram.

\subsubsection{Information System Architecture}

Tahapan ini melakukan perancangan arsitektur sistem informasi SMA Negeri 1 Watubangga, dengan membangun aristektur data dari tabel detail entitas data

TABEL III

Detail EnTITAS Data

\begin{tabular}{|l|l|}
\hline Kandidat entitas & Entitas \\
\hline $\begin{array}{l}\text { Penerimaan peserta } \\
\text { didik baru (PPPBD) }\end{array}$ & $\begin{array}{l}\text { 1. Penjadwalan } \\
\text { 2. Pendaftaran } \\
\text { 3. Test } \\
\text { 4. Pelaporan penerimaan peserta didik } \\
\text { baru(PPPBD) }\end{array}$ \\
\hline $\begin{array}{l}\text { Proses belajar } \\
\text { mengajar (PBM) }\end{array}$ & $\begin{array}{l}\text { 1. Siswa } \\
\text { 2. Wali kelas } \\
\text { 3. Jadwal } \\
\text { 4. Absen/daftar hadir } \\
\text { 5. Nilai }\end{array}$ \\
\hline $\begin{array}{l}\text { Manajemen data } \\
\text { lulusan }\end{array}$ & $\begin{array}{l}\text { 1. Kelulusan } \\
\text { 2. pembuatan ijazah } \\
\text { 3. pengelolaan perpisahan } \\
\text { 4. laporan }\end{array}$ \\
\hline
\end{tabular}


Pemodelan Arsitektur Enterprise Menggunakan Metode Togaf Adm

\begin{tabular}{|l|l|}
\hline Manajemen tata & $\begin{array}{l}\text { 1. pengelolaan } \\
\text { usaha (MTU) }\end{array}$ \\
& $\begin{array}{l}\text { 2. } \text { rekapitulasi } \\
\text { 3. pencatatan }\end{array}$ \\
\hline Manajemen sarana & 1.pengadaan \\
dan prasarana & 2.inventaris aset \\
(MPS) & 3.laporan aset \\
\hline Manajemen & 1. perencanaan \\
keuangan (MK) & 2. penerimaan \\
& 3. pengeluaran \\
& 4. pengalokasian \\
& 5. laporan \\
\hline
\end{tabular}

\begin{tabular}{|l|l|l|l|l|l|l|l|l|}
\hline \multicolumn{2}{|l|}{} & PPDB & PBM & MDT & $\begin{array}{l}\text { AL } \\
\text { UM } \\
\text { NI }\end{array}$ & MTU & $\begin{array}{c}\text { MS } \\
\text { P }\end{array}$ & MK \\
\hline & PPDB & Replace & & & & & & \\
\hline PBM & & Replace & & & & & \\
\hline & MDT & & & Add & & & & \\
\cline { 2 - 9 } & & & & Add & & & \\
\hline
\end{tabular}

\subsubsection{Technology Architecture}

Pada tahapan ini menggambarkan aliran informasi antar sistem aplikasi.

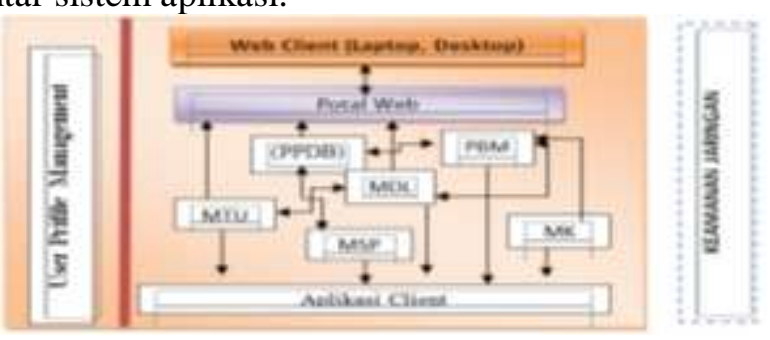

Gambar 4. Aliran informasi antar sistem aplikasi.

Berdasarkan keragaman pengembangan jarigan dan kondisi ekseting teknologi, maka disipakan skestsa pengembangan jaringan, terlihat pada gambar berikut:

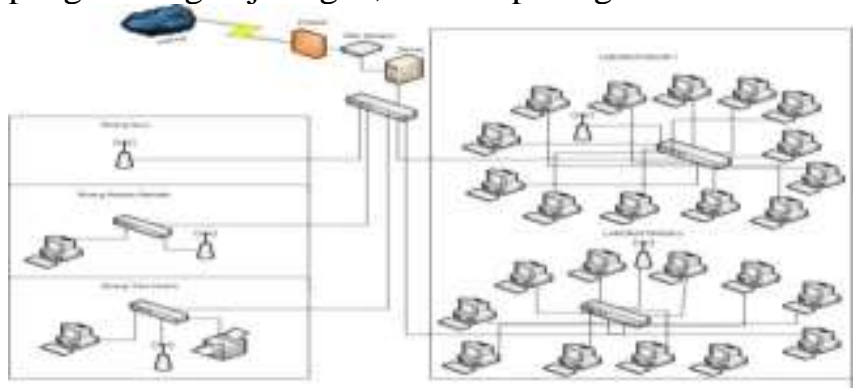

Gambar 5..Infrastructure Topologi

\subsubsection{Oppurtunities and solution}

Gap analisis antara sistem informasi dan gap analisis teknologi perangkat lunak yang ada saat ini dan kondisi yang akan datang. Sistem informasi yang baru (add) dan informasi yang dapat diperbaharui (replace). terlihat pada tabel berikut:

TABEL IV

ANALISIS Gap Sistem Dan TeKNOLOGI

\begin{tabular}{|l|l|}
\hline & Future \\
\hline
\end{tabular}

\subsubsection{Migration Planning}

Pada tahapan ini migrasi harus dipersiapakan sebaik mungkin, sangat penting untuk menjaga data yang sudah ada tetap dapat digunakan pada perencanaan sistem baru ini. Aplikasi-aplikasi yang terkait dalam penelitian ini dapat dikelompokkan sebagai berikut:

TABEL V

URUTAN IMPLEMENTASI APLIKASI

\begin{tabular}{|c|c|c|}
\hline $\begin{array}{c}\text { No. Urut } \\
\text { implementasi }\end{array}$ & Model aplikasi & $\begin{array}{l}\text { Kode } \\
\text { aplikasi }\end{array}$ \\
\hline \multirow{4}{*}{1} & $\begin{array}{l}\text { Pendaftaran Aplikasi } \\
\text { PPDB }\end{array}$ & A-1.1 \\
\hline & Penjadwalan PPDB & A-1.2 \\
\hline & $\begin{array}{l}\text { Pengelolaan nilai seleksi } \\
\text { PPDB }\end{array}$ & A-1.3 \\
\hline & Pembuatan laporan PPDB & A-1.4 \\
\hline \multirow{5}{*}{2} & Pengelolaan data siswa & A-2.1 \\
\hline & Wali kelas & A-2.2 \\
\hline & Jadwal mata pelajaran & A-2.3 \\
\hline & Absen/daftar hadir & A-2.4 \\
\hline & Pengelolaan nilai & A-2.5 \\
\hline \multirow{3}{*}{3} & $\begin{array}{l}\text { Pengelolaan syarat } \\
\text { kelulusan }\end{array}$ & A-3.1 \\
\hline & Pembuatan ijazah & A-3.2 \\
\hline & Pengelolaan perpisahan & A-3.3 \\
\hline \multirow{4}{*}{4} & Pengelolaan data & A-4.1 \\
\hline & Pelaporan rekapitulasi guru & A-4.2 \\
\hline & $\begin{array}{l}\text { Pencatatan kepangkatan } \\
\text { guru }\end{array}$ & A-4.3 \\
\hline & Laporan kepangkatan & A-4.4 \\
\hline \multirow{3}{*}{5} & Aplikasi inventaris asset & A-5.1 \\
\hline & $\begin{array}{l}\text { Pengelolaan pengadaan } \\
\text { aset }\end{array}$ & A-5.2 \\
\hline & Pembuatan laporan asset & A-5.3 \\
\hline \multirow[b]{4}{*}{6} & Perencanaan keuangan & A-6.1 \\
\hline & Penerimaan & A-6.2 \\
\hline & Pengeluaran & A-6.3 \\
\hline & Pengalokasian & A-6.4 \\
\hline
\end{tabular}




\begin{tabular}{|c|lc|c|}
\hline & $\begin{array}{l}\text { Pembuatan } \\
\text { keuangan }\end{array}$ & laporan & A.5 \\
\cline { 2 - 3 } & Lapangan & A-6.6 \\
\hline
\end{tabular}

\section{KESIMPULAN}

Berdasarkan hasil pembahasan yang telah disampaikan sesuia dengan tahapan penelitian,maka disimpulkan sebagai berikut:

1. Dengan menggunakan metodologi TOGAF ADM sebagai kerangka kerja dalam pemodelan arsiterktur enterprise SMA negeri 1 watubangga, menghasilkan analisis proses bisnis yang terdiri dari pelayanan penerimaan peserta didik baru (PPDB), proses belajar mengajar (PBM), manajemen data lulusan (MDL), manajemen tata usaha (MTU), manajemen sarana prasarana (MSP), manajemen keuangan (MK) telah sesuai dengan visi misi organisasi.

2. Blue print yang dihasilkan dapat diimplementasikan secara bertahap berdasarkan prioritas aplikasi yang dibutuhkan.

3. Pemodelan arsitektur sistem informasi yang diberikan memunculkan kerangka pengembangan sistem informasi yang berisi roadmap hasil perencanaan untuk perancangan sistem informasi (blue print).

\section{UCAPAN TERIMA KASIH}

Terima kasih kepada Universitas Sembilanbelas November Kolaka yang telah menaungi dalam penelitian ini.Terima kasih pula kepada pihak SMA Negeri 1 Watubangga yang telah memberikan bantuan dan dukungan hingga akhir penelitian ini.

\section{DAFTAR PUSTAKa}

Kustiyaningsih Yeni, Perencanaan Arsitektur Enterprise menggunkan TOGAF ADM (studi kasus : RSUD dr.soegiri lamongan), 2013.

Widyaningsih Novia, Perencanaan Arsitektur Enterprise menggunakan TOGAF Versi 4 Studi Kasus : Dewan Kehormatan Penyelenggara Pemilu (DKPP), 2014.

Rosyidi Rahman, Purwadi, Perancangan Pengembangan Arsitektur Sistem Informasi Akademik Dengan Menggunakan Togaf (Studi Kasus Stimik Amikom Perwekerto), 2014.

Rufaida, R, Perancangan Arsitektur Teknologi Informasi Rumah Sakit dengan TOGAF Studi Kasus: RSMB, Jurnal Sarjana Institute Teknologi Bandung Bidang Teknologi Elektro dan Informatika, Vol.1, No.1, April 2012.

Surya , \& G, F.S, Penerapan TOGAF Architecture Development Method pada Adopsi Cloud Computing Perguruan Tinggi,
Proceedings Konversi Nasional Sistem Informasi (KNSI) 328, ISBN 978-602-17488-0-0, Februari 2013.

The Open Group, The Open Group Architecture Framework (TOGAF), 2007

The Open Group, TOGAF Version 9 The Open Group Architecture Framework (TOGAF)

Yunis, R \&Theodora, Penerapan Enterprise Architecture Framework untuk Pemodelan Sistem Informasi, ISSN 14120100 Vol.13, No.2, Oktober 2012.

Supriyana.I, Sistem Informasi dan Arsitektur Teknologi dengan menggunakan TOGAF Studi Kasus:Bakosurtanal, Jurnal Generic Vol.5, No.1, Januari 2010. 
Pemodelan Arsitektur Enterprise Menggunakan Metode Togaf Adm 